\title{
The effect of different types of honey on the lipid profile of streptozotocin-induced diabetic rats
}

\author{
Ali Mohammadimanesh ${ }^{1}$, Ali Asghar Vahidiniya ${ }^{1}$, Saeid Doaei ${ }^{2,3,4}$, Maryam Gholamalizadeh, \\ Zahra Shahvegharas ${ }^{5}$, Iraj Salehi ${ }^{6}$, Nasrin Fayyaz ${ }^{7}$, Hassan Mozzaffari Khosravi ${ }^{1}$
}

\author{
${ }^{1}$ Nutrition Department, School of Public Health, Shahid Sadoughi University of \\ Medical Sciences, Yazd, Iran \\ ${ }^{2}$ Research Centre of Health and Environment, Guilan University of Medical Sciences, \\ Rasht, Iran \\ ${ }^{3}$ Natural Products and Medicinal Plants Research Centre, North Khorasan University \\ of Medical Sciences, Bojnurd, Iran. \\ ${ }^{4}$ Student Research Committee, Cancer Research Centre, Shahid Beheshti University \\ of Medical Sciences, Tehran, Iran. \\ ${ }^{5}$ Faculty of Nutrition Sciences, Tabriz University of Medical Sciences, Tabriz, Iran \\ ${ }^{6}$ Nauru Sciences Research Centre, Hamedan University of medical sciences, Hamedan, \\ Iran \\ ${ }^{7}$ Department of Food Science and Technology, Faculty of Agriculture, \\ Ferdowsi University of Mashhad, Mashhad, Iran
}

Submitted: 15 August 2018

Accepted: 11 December 2018

Arch Med Sci Atheroscler Dis 2019; 4: e113-e118

DOI: https://doi.org/10.5114/amsad.2019.85409

Copyright $\odot 2019$ Termedia \& Banach

\section{Abstract:}

Introduction: The effect of honey consumption in diabetic patients has been contradictory. The aim of the present animal study was to compare the effect of different types of honey on the lipid profile in diabetic rats.

Material and methods: Sixty-four male Wistar rats were divided into two main groups: a streptozotocin-induced diabetes mellitus (DM) group (including four subgroups) and a healthy group (including four subgroups), based on random allocation. Three subgroups of each main group were given $1 \mathrm{mg} / \mathrm{kg}$ of three different types of honey (acacia, astragalus, and artificial honey) by oral gavage for 10 weeks. The control groups were given distilled water. Blood samples were collected, and the lipid profile was measured and compared between the eight groups after the intervention.

Results: The levels of LDL, triglycerides (TG), and total cholesterol (Tchol) in DM rats treated with astragalus honey were significantly lower and the HDL level was significantly higher compared to the other DM and healthy groups (all $p$-values $<0.05$ ). LDL, TG, and Tchol levels in DM rats treated with artificial honey were significantly higher, and HDL levels were significantly lower than for other types of honey and for the control groups (all $p$-values $<0.05$ ). LDL, HDL, TG, and Tchol levels in healthy rats were not significantly different between the groups ( $p$-value $>0.05$ ).

Conclusions: Different types of honey (acacia, astragalus, and artificial honey) had various effects on serum lipid profiles in diabetic rats. The results of this study indicated that the effect of honey on diabetic patients can vary widely based on its source.

Key words: diabetes mellitus, lipid profile, honey.

\author{
Corresponding author: \\ Hassan Mozzaffari Khosravi \\ Nutrition Department \\ School of Public Health \\ Shahid Sadoughi \\ University \\ of Medical Sciences \\ Yazd, Iran \\ Phone: 0216653265 \\ E-mail: mozaffari.kh@gmail. \\ com
}




\section{Introduction}

The number of diabetic patients is rising along with increased prevalence of obesity and physical inactivity. The global prevalence of diabetes has risen from $4.7 \%$ in 1980 to $8.5 \%$ in 2014 [1]. In 2005, the prevalence of diabetes mellitus (DM) in Iran was 7.7\% (about 2 million people) [2]. It is predicted that 5.2 million Iranian people will have DM in 2025 [3]. Diabetes mellitus patients are not allowed to consume sweets because of their adverse effects on blood glucose [4]. Proper dietary alternatives for diabetic patients can be used as one of the available therapeutic strategies that give the patient a sense of satisfaction in addition to controlling blood glucose $[5,6]$. Honey is suggested as a safe alternative sweetener for diabetic patients [7].

Moreover, DM is associated with decreased levels of serum insulin, increased lipolysis in adipose tissue, increased fatty acid content in the liver, and increased synthesis of endogen triglycerides (TG) [8-10]. Recent studies have shown that honey may have beneficial effects on the lipid profile in DM patients [11-14]. However, the results of some other studies have not confirmed the beneficial effects of honey $[15,16]$. These differences in the results of studies may be due to differences in the nutritional and non-nutritional components of the different types of honey $[17,18]$. For example, antioxidant activity and phenolic contents were reported to be higher among Yemeni honey, Acacia edgeworhi honey, Ziziphus spina-christi honey, tropical blossom honey, American-orange source honey, and Iranian-tropical honey [19]. Another study showed that natural origin of the honey determines its chemical components, such as trace elements including $\mathrm{Co}, \mathrm{Cu}, \mathrm{F}, \mathrm{Fe}, \mathrm{I}, \mathrm{Mn}, \mathrm{Ni}$, $\mathrm{Sr}$, and $\mathrm{Zn}$ as well as macro minerals, including $\mathrm{Cl}$, $\mathrm{Na}, \mathrm{K}$, and $\mathrm{Mg}$ [20]. The level of effective factors of honey such as antioxidants, anti-tyrosinase, and anti-bacterial agents are also different among the different types of honey [21].

This study aimed to investigate the effect of three types of honey (acacia, astragalus, and artificial honey) on serum lipid profile in DM and healthy rats.

\section{Material and methods}

This experimental study conducted on 64 male Wistar rats to compare the effects of acacia, astragalus, and artificial honey on the level of serum low-density lipoprotein ( $L D L)$, high-density lipoprotein (HDL), TG, and total cholesterol (Tchol) levels in type $1 \mathrm{DM}$ and healthy rats. The subjects were 64 male Wistar rats aged 12-14 weeks and weighing 180 to $200 \mathrm{~g}$, which were purchased from the Pasteur Institute, Tehran, Iran. The inclu- sion criterion was weight between 180 and $200 \mathrm{~g}$, and the exclusion criteria were animal illness or death during the study.

The research was carried out at the animal lab of Hamadan University of Medical Sciences, Hamedan, Iran. According to previous studies, eight rats were considered for each group. Therefore, the total number of required rats was 64 for eight groups. There was no significant difference between the average weight of the rats in the groups. Two main groups, defined as the diabetic group and the healthy group, and each main group included four subgroups. Three subgroups of each main group were given $1 \mathrm{mg} / \mathrm{kg}$ of three types of honey (acacia, astragalus, and artificial honey) by oral gavage for 10 weeks, and distilled water was given to the control groups. Rats from each group were placed in two separate cages containing four rats. The rats were kept in standard conditions for 1 week to comply with the new environmental conditions. These conditions included an environment temperature of $20^{\circ} \mathrm{C}, 12 \mathrm{~h}$ of light and $12 \mathrm{~h}$ of darkness, the body and floor of the cages were made of plastic, and the doors were made of metal. Enough bangs were poured under the cages for having cleanliness and absorbing the moisture of urine and stools of animals, and the bangs were replaced every day for all groups. Dishes of water and food were placed on a metal shelf (cage door) in a specific place and were freely available for the animals.

\section{Diabetes mellitus induction}

Streptozotocin (STZ) was used to induce type $1 \mathrm{DM}$ in rats. $60 \mathrm{mg} / \mathrm{kg}$ STZ was dissolved in $1 \mathrm{ml}$ normal saline and injected intraperitoneally. Before the injection of STZ, the rats were weighed to determine the required amount of STZ. The blood glucose was monitored by glucometer three days after STZ injection, to confirm DM. A blood drop was obtained from the veins of the tail zone and placed on a glucometer strip to measure the amount of blood glucose. Only animals that had a plasma glucose level over 200 mg/dl were considered as DM. Four other groups were included the study as non-diabetic controls.

\section{Intervention}

Two types of honey (acacia and astragalus) were purchased from Hanita company, and artificial honey was obtained from a local producer in Yazd, Iran. The different types of honey or distilled water were given for 75 days to the eight groups by a special tube and a precision syringe gavage as follows: $A-D M$ control group receiving $0.5 \mathrm{ml}$ water per day, B - DM group receiving $1 \mathrm{~g} / \mathrm{kg}$ astragalus honey, $\mathrm{C}-\mathrm{DM}$ group receiving $1 \mathrm{~g} / \mathrm{kg}$ aca- 
cia honey, D - DM group receiving $1 \mathrm{~g} / \mathrm{kg}$ artificial honey, $\mathrm{E}$ - healthy control group receiving $0.5 \mathrm{ml}$ water per day, $\mathrm{F}$ - healthy control group receiving $1 \mathrm{~g} / \mathrm{kg}$ astragalus honey, $\mathrm{G}$ - healthy control group receiving $1 \mathrm{~g} / \mathrm{kg}$ acacia honey, and $\mathrm{H}$ - healthy control group receiving $1 \mathrm{~g} / \mathrm{kg}$ artificial honey.

Seventy-five days after the intervention, the rats were kept fasting for $16 \mathrm{~h}$. The FBG was detected through direct puncture of the heart. Then the rats were then killed with ether. The final weight of the rats was measured using a validated scale. All the primary outcomes were measured by Enzyme-linked immunosorbent assay (ELISA), based on the instruction provided by the manufacturer of each kit.

\section{Ethical considerations}

This study was approved by the Ethics Committee of Shahid Sadoughi University of Medical Sciences in Yazd, Iran.

\section{Statistical analysis}

One-way analysis of variance was used to compare the mean serum levels of lipid profile between the eight groups. Statistical analysis of the data was performed using SPSS software version 16 (Chicago, IL, USA), and $p<0.05$ was considered significant.

\section{Results}

Table I shows the LDL, HDL, TG, and Tchol levels of the three intervention groups and the control group in DM rats.

The mean LDL levels in DM rats were signifi- cantly different between the groups ( $p=0.001$ ). The mean level of LDL in DM rats treated with artificial honey was significantly higher than that seen in the other groups. Post hoc analysis indicated a significant difference in the mean level of LDL in rats treated with artificial honey compared to all other study groups $(p=0.001)$. The mean LDL level in DM rats treated with astragalus honey was significantly lower compared to all other groups, which indicates a beneficial effect of astragalus honey on the LDL level of DM rats compared to the other types of honey (Table I).

Moreover, there was a significant difference between four groups according to the findings on HDL levels $(p=0.001)$. The mean level of HDL in DM rats treated with artificial honey was lower than for other types of honey and control groups. The post hoc analysis indicated a significant difference in the mean level of HDL in rats treated with artificial honey compared to astragalus honey and the control groups $(p<0.05)$. Finally, the post hoc test indicated that the mean HDL level in DM rats treated with astragalus honey was higher compared to all the other groups, which confirmed the higher quality of astragalus honey in this regard compared to other types of honey. The astragalus honey group showed the highest and the artificial honey group showed the lowest levels of $\mathrm{HDL}$ among all four groups. Indeed, in DM subgroups, artificial honey decreased (49\%) and astragalus honey increased (3.5\%) HDL-cholesterol levels compared to the DM control subgroup (Table I).

The mean of Tchol levels in DM rats was also significantly different between the groups ( $p=$ 0.002) (Table II). The mean level of Tchol in DM rats treated with artificial honey was higher than

Table I. Comparison of mean LDL, HDL, TG, and Tchol levels of honey recipient groups in DM rats (mg/dl)

\begin{tabular}{|lcccccc|}
\hline Parameter & $\begin{array}{c}\text { Acacia group } \\
\text { Mean } \pm \text { SD }\end{array}$ & $\begin{array}{c}\text { Astragalus group } \\
\text { Mean } \pm \text { SD }\end{array}$ & $\begin{array}{c}\text { Artificial honey } \\
\text { group } \\
\text { Mean } \pm \text { SD }\end{array}$ & $\begin{array}{c}\text { Control group } \\
\text { Mean } \pm \text { SD }\end{array}$ & $F$ value & $P$-value \\
\hline LDL & $22.00 \pm 13.53$ & $11.42 \pm 4.70$ & $48.28 \pm 10.8$ & $14.94 \pm 10.80$ & 17.693 & 0.001 \\
\hline HDL & $23.00 \pm 8.80$ & $33.00 \pm 7.10$ & $16.8 \pm 2.20$ & $31.90 \pm 6.70$ & 8.133 & 0.001 \\
\hline TG & $70.25 \pm 32.90$ & $50.00 \pm 27.10$ & $115.00 \pm 31.30$ & $62.40 \pm 16.60$ & 6.045 & 0.004 \\
\hline Tchol & $56.12 \pm 16.30$ & $50.00 \pm 26.60$ & $115.00 \pm 9.20$ & $62.40 \pm 10.20$ & 7.077 & 0.002 \\
\hline
\end{tabular}

Table II. Comparison of mean LDL, HDL, TG, and Tchol levels of the groups of healthy rats receiving honey (mg/dl)

\begin{tabular}{|lcccccc|}
\hline Parameter & $\begin{array}{c}\text { Acacia group } \\
\text { Mean } \pm \text { SD }\end{array}$ & $\begin{array}{c}\text { Astragalus group } \\
\text { Mean } \pm \text { SD }\end{array}$ & $\begin{array}{c}\text { Artificial honey } \\
\text { group } \\
\text { Mean } \pm \text { SD }\end{array}$ & $\begin{array}{c}\text { Control group } \\
\text { Mean } \pm \text { SD }\end{array}$ & $F$ value & $P$-value \\
\hline LDL & $45.86 \pm 44.90$ & $36.65 \pm 22.10$ & $52.62 \pm 14.40$ & $48.48 \pm 19.10$ & 0.475 & 0.702 \\
\hline HDL & $19.65 \pm 9.90$ & $16.06 \pm 6.80$ & $14.25 \pm 4.00$ & $15.60 \pm 4.60$ & 0.920 & 0.444 \\
\hline TG & $134.00 \pm 34.20$ & $124.75 \pm 53.00$ & $116.62 \pm 36.90$ & $104.75 \pm 31.30$ & 0.780 & 0.515 \\
\hline Tchol & $82.00 \pm 10.20$ & $84.00 \pm 15.30$ & $89.75 \pm 12.80$ & $86.25 \pm 16.60$ & 0.451 & 0.718 \\
\hline
\end{tabular}


for the other types of honey and the control groups. Post hoc analysis indicated a difference in the mean level of Tchol in rats treated with Nodoosh honey in comparison to the astragalus and acacia honey groups $(p<0.05)$ (Table I).

Moreover, the mean TG levels among DM rats were significantly different between the groups $(p=0.004)$. The mean level of TG in DM rats treated with artificial honey was higher than for other types of honey and the control group. Post hoc analysis indicated a difference in the mean level of TG in rats treated with artificial honey compared to astragalus, acacia honey, and control groups $(p<0.05)$. Finally, the post hoc test indicated that the mean TG level in DM rats treated with astragalus honey was lower compared to all other groups (Table II).

Table II shows the LDL, HDL, TG, and Tchol levels of the three intervention groups and the control group in healthy rats. There was no significant difference between the mean level of LDL, HDL, Tchol, and TG in healthy rats treated with different types of honey and the control group.

\section{Discussion}

The results of this study showed that the type of honey consumed has an effect on the serum lipid profile of diabetic rats. Astragalus honey decreased LDL, TG, and Tchol levels and increased HDL levels, and artificial honey increased LDL, TG, and Tchol levels and decreased HDL levels in DM rats. In healthy subgroups, the effects of three types of honey were not significantly different. Some other studies have reported a positive effect of the astragalus plant on blood lipid profile [22-26], which is consistent with our findings. For example, Liao et al. reported that astragalus extracts could increase HDL in streptozotocin-induced diabetic rats. They believed that this effect of astragalus was due to its polysaccharides [24, 25]. It is reasonable that the beneficial effects of astragalus honey consumption in increasing HDL levels in DM rats can be attributed to its components. The abilities of each honey to modify the serum lipid profile is suggested to be related to its specific components [27]. In general, fructose has been reported as a stimulant for insulin secretion from pancreatic cells [28]. However, the effect of other active ingredients in honey could enhance or decline the effects of fructose [27]. Najafian et al. reported that flavonoids are one of the most important components of honey [29]. Trans-chalcone in honey acts as a mediator in the biosynthesis of flavonoids. The beneficial effect of trans-chalcone on the lipid profile in streptozotocin-induced diabetic rats was previously reported [30]. Wang et al. conducted a study on flavonoids of astragalus extracts and concluded that these flavo- noids reduced Tchol and LDL and increased HDL. They recognised the effective flavonoids of plant extracts, including: $\beta$-sitosterol, formononetin, calycosin, daucosterol, formononetin-7-O- $\beta$-D-glucopyranoside, and calycosin-7-O- $\beta$-D-glucopyranoside [31]. According to the results, there was a significant difference between the effects of different honeys on serum Tchol. Tchol in the artificial honey group was the highest and in the astragalus honey group it was the lowest, among the four intervention subgroups. There are few studies on the effect of different honeys on Tchol levels. Mushtaq et al. reported beneficial effects of natural honey on Tchol in a clinical study [32], in line with some other studies [32-35]. In the DM honey subtypes, but not in the healthy groups, artificial honey increased the Tchol level by $14 \%$ and astragalus reduced it by $34 \%$. It seems that honey exerts its effects only in subjects with diabetes.

The effect of different honey types on serum LDL levels was significantly different, as the artificial honey group led to the highest and the astragalus honey group led to the lowest levels of LDL among all four DM groups. In fact, in the DM subtypes groups, LDL cholesterol levels were decreased by $23 \%$ in the Astragalus honey group and increased by $23 \%$ in the artificial honey group. This difference was observed only in DM rats, and the effect of the three types of honey on LDL was not significant in healthy subgroups. Lu et al. also reported that the astragalus extract decreased Tchol, TG, and LDL [35].

Based on the results of this study, there was a significant difference in TG levels between the effects of these honeys in the DM group. The artificial honey group had the highest and the astragalus honey group had the lowest levels of TG among all four DM groups after intervention. This difference was seen only in DM rats, and the effect of the three honey types was not significant in the healthy subgroups. A similar study showed that administration of gelam honey at dose of 5000 $\mathrm{mg} / \mathrm{kg}$ to male rats for 14 days decreased TG levels. This study suggested that the honey might have good effects on blood TG levels and that polyphenol contents of honey may be attributed to the reduction of the TG level [36]. Recent studies reported that artificial honey in patients with hypertriglyceridaemia and hyperlipidaemia increased TG and LDL, while natural honey decreased both of them [37, 38], which is in line with the present study.

However, our study had some limitations. We did not measure the level of lipid profile at baseline. So, we only compared the level of TG, Tchol, and LDL between different diabetic and healthy groups at the end of the study. Further studies with before and after measurements are needed 
to identify the role of active components of honey and provide proper dietary recommendations to diabetic patients.

In conclusion, the results of this study showed that the different types of honey could have different effects on serum lipid profile. Astragalus honey decreased LDL, TG, and Tchol levels and increased HDL level in DM rats. On the other hand, artificial honey increased LDL, TG, and Tchol levels and decreased HDL level in DM rats. Further studies are needed to identify active components in different honeys and to provide proper dietary recommendations in this area.

\section{Acknowledgments}

This article is adapted from a research project approved by research committee of Yazd University of Medical Sciences, Yazd, Iran. (Code 13115). All colleagues in this university are warmly appreciated for their immense support and contribution.

\section{Conflict of interest}

The authors declare no conflict of interest.

\section{References}

1. Mathers CD, Loncar D. Projections of global mortality and burden of disease from 2002 to 2030. PLoS Med 2006; 3: e442.

2. Esteghamati A, Gouya MM, Abbasi M, et al. Prevalence of diabetes and impaired fasting glucose in the adult population of Iran: National Survey of Risk Factors for Non-Communicable Diseases of Iran. Diabetes Care 2008; 31: 96-8.

3. King H, Aubert RE, Herman WH. Global burden of diabetes, 1995-2025: prevalence, numerical estimates, and projections. Diabetes Care 1998; 21: 1414-31.

4. Kemmer FW, Bisping R, Steingrüber HJ, et al. Psychological stress and metabolic control in patients with type I diabetes mellitus. N Engl J Med 1986; 314: 1078-84.

5. Low LL, Tong SF, Low WY. Selection of treatment strategies among patients with type 2 diabetes mellitus in Malaysia: a grounded theory approach. PLoS One 2016; 11: e0147127.

6. Vahid F, Shivappa N, Karamati M, Naeini AJ, Hebert JR, Davoodi SH. Association between Dietary Inflammatory Index (DII) and risk of prediabetes: a case-control study. Appl Physiol Nutr Metab 2016; 42: 399-404.

7. Tul-Noor Z, Khan TA, Mejia SB, de Souza R, Sievenpiper JL. The effect of honey intake on lipid risk factors: a systematic review and meta-analysis of controlled trials. FASEB J 2017; 31 (1 Suppl): 966-23.

8. Pan DA, Lillioja S, Kriketos AD, et al. Skeletal muscle triglyceride levels are inversely related to insulin action. Diabetes 1997; 46: 983-8.

9. Chepulis L, Starkey N. The long-term effects of feeding honey compared with sucrose and a sugar-free diet on weight gain, lipid profiles, and DEXA measurements in rats. J Food Sci 2008; 73: H1-7.

10. Brunzell JD, Porte Jr D, Bierman EL. Abnormal lipoprotein-lipase-mediated plasma triglyceride removal in un- treated diabetes mellitus associated with hypertriglyceridemia. Metabolism 1979; 28: 901-7.

11. Al-Waili NS. Natural honey lowers plasma glucose, C-reactive protein, homocysteine, and blood lipids in healthy, diabetic, and hyperlipidemic subjects: comparison with dextrose and sucrose. J Med Food 2004; 7: 100-7.

12. Ramli N, Chin KY, Zarkasi K, Ahmad F. A review on the protective effects of honey against metabolic syndrome. Nutrients 2018; 10: pi: E1009.

13. Bobiş O, Dezmirean DS, Moise AR. Honey and diabetes: the importance of natural simple sugars in diet for preventing and treating different type of diabetes. Oxid Med Cellular Longevity 2018; 2018: 4757893.

14. Meo SA, Ansari MJ, Sattar K, Chaudhary HU, Hajjar W, Alasiri S. Honey and diabetes mellitus: obstacles and challenges - road to be repaired. Saudi J Biol Sci 2017; 24: 1030-3.

15. Fasanmade AA, Alabi OT. Differential effect of honey on selected variables in alloxan-induced and fructose-induced diabetic rats. Afr J Biomed Res 2008; 11: 191-6.

16. Abdulrhman MA. Honey as a sole treatment of type 2 diabetes mellitus. Endocrinol Metab Syndr 2016; 5: 232.

17. Solayman M. Physicochemical properties, minerals, trace elements, and heavy metals in honey of different origins: a comprehensive review. Compr Rev Food Sci Food Safety 2016; 15: 219-33.

18. Al-Mamary M, Al-Meeri A, Al-Habori M. Antioxidant activities and total phenolics of different types of honey. Nutr Res 2002; 22: 1041-7.

19. Rashed M, Soltan M. Major and trace elements in different types of Egyptian mono-floral and non-floral bee honeys. J Food Comp Analysis 2004; 17: 725-35.

20. Jantakee K, Tragoolpua Y. Activities of different types of Thai honey on pathogenic bacteria causing skin diseases, tyrosinase enzyme and generating free radicals. Biol Res 2015; 48: 4.

21. Bahrami M, Ataie-Jafari A, Hosseini S, Foruzanfar MH, Rahmani M, Pajouhi M. Effects of natural honey consumption in diabetic patients: an 8-week randomized clinical trial. Int J Food Sci Nutr 2009; 60: 618-26.

22. Jiangwei MA, Zengyong $Q, X i a X$. Aqueous extract of Astragalus mongholicus ameliorates high cholesterol diet induced oxidative injury in experimental rats models. J Med Plants Res 2011; 5: 855-8.

23. Rogers ME, Bohlken RM, Beets MW, Hammer SB, Ziegenfuss TN, Šarabon N. Effects of creatine, ginseng, and astragalus supplementation on strength, body composition, mood, and blood lipids during strength-training in older adults. J Sports Sci Med 2006; 5: 60-9.

24. Samarghandian S, Farkhondeh T, Samini F. Honey and health: a review of recent clinical research. Pharmacognosy Res 2017; 9: 121-7.

25. Liao W, Shi Y. Effect of Astragalus polysaccharides and soy isoflavones on glucose metabolism in diabetic rats.

26. Li J, Qu WJ, Liu C, Shi DH. Effect of Lycium ruthenicum pigment on blood lipids level and lipid peroxidation in mice with hyperlipemia. Food Sci 2007; 9.

27. Abdulrhman MM, El-Hefnawy MH, Aly RH, et al. Metabolic effects of honey in type 1 diabetes mellitus: a randomized crossover pilot study. J Med Food 2013; 16: 66-72.

28. Grodsky GM, Batts AA, Bennett LL, Vcella C, Mcwilliams NB, Smith Df. Effects of carbohydrates on secretion of insulin from isolated rat pancreas. Am J Physiol 196; 2015 : 638-44.

29. Najafian M, Ebrahim-Habibi A, Yaghmaei P, Parivar K, Larijani B. Core structure of flavonoids precursor as an 
antihyperglycemic and antihyperlipidemic agent: an in vivo study in rats. Acta Biochim Pol 2010; 57: 55-60.

30. Lo Piparo E, Scheib H, Frei N, Williamson G, Grigorov $\mathrm{M}$, Chou CJ. Flavonoids for controlling starch digestion: structural requirements for inhibiting human alpha-amylase. J Med Chem 2008; 51: 3555-61.

31. Wang D, Zhuang Y, Tian Y, Thomas GN, Ying M, Tomlinson B. Study of the effects of total flavonoids of Astragalus on atherosclerosis formation and potential mechanisms. Oxid Med Cell Longevity 2012; 201: 209843.

32. Mushtaq R, Mushtaq R, Khan ZT. Effects of natural honey on lipid profile and body weight in normal weight and obese adults: a randomized clinical trial. Pakistan J Zool 2011; 43: 161-9.

33. Bahrami M, Ataie-Jafari A, Hosseini S, Foruzanfar MH, Rahmani M, Pajouhi M. Effects of natural honey consumption in diabetic patients: an 8-week randomized clinical trial. Int J Food Sci Nutr 2009; 60: 618-26.

34. Adnan F, Sadiq M, Jehangir A. Anti-hyperlipidemic effect of acacia honey (desi kikar) in cholesterol-diet induced hyperlipidemia in rats. Biomedica 2011; 27: 62-7.

35. Lu Y, Li JZ, Zheng X. Effect of Astragalus Angelica mixture on serum lipids and glomerulosclerosis in rats with nephrotic syndrome. Zhongguo Zhong Xi Yi Jie He Za Zhi 1997; 17: 478-80.

36. Samat S, Mohd Nor N, Hussein FN, Eshak Z, Ismail WIW. Short-term consumption of Gelam honey reduces triglyceride level. Int Food Res J 2017; 24: 1519-24.

37. Bogdanov S, Jurendic T, Sieber R, Gallmann P. Honey for nutrition and health: a review. J Am Coll Nutr 2008; 27: 677-89.

38. Asaduzzaman M, Sohanur Rahman M, Munira S, et al. Effects of honey supplementation on hepatic and cardiovascular disease (CVD) marker in streptozotocin-induced diabetic rats. J Diabetes Metab 2015; 6: 592. 